\title{
Modeling and Simulation of 2 MW PMSG Wind Energy Conversion Systems
}

\author{
Prerna Badoni ${ }^{1}$, S. Bhanu Prakash ${ }^{2}$ \\ ${ }^{1,2}$ Department of Electrical Engineering, D.I.T University, Dehradun, India,
}

\begin{abstract}
This paper represents the modeling and simulation of $2 M W$ Direct Drive PMSG Wind energy conversion system (WECS). The modelling of wind turbine and PMSG is carried out in simulink to determine its parameter. WECS consists different components namely Wind turbine, Generator, rectifier-inverter, controller system including transformer, grid etc. The PMSG and converter model are established in the d-q model.
\end{abstract}

Keywords: PMSG, WECS, Wind turbine, rectifier, inverter, MATLAB/SIMLINK, transformer, Grid.

\section{INTRODUCTION}

In these days two types of generator used in large scale WECS for convert the wind power into electrical power which are doubly fed induction generator (DFIG) and Permanent magnet synchronous generator (PMSG). PMSG is a Direct Drive type generator; and don't require gear box and excitation current so PMSG show good performance in WECS. MATLAB/SIMULINK is a graphical software package for modeling, and simulating WECS system [1]. WECS with PMSG can avoid the problem of wear and tear of gear, it can help wind turbine operate more reliable and reduce maintenance [2]. The paper represents a 2 MW variable PMSG WECS with the control strategy. WECS can be used in two different ways namely isolated standalone system and Grid connected system. Standalone systems are employed to the needs of small scale industries for rulers areas, such system are located at for off places/remote areas. Grid connected system increased energy efficiency, robustness, voltage support, diversification of energy sources, reduced transmission and distribution losses and reliability of the system. This paper described the model and simulation of PMSG based on WECS in d-q model

\section{Block Diagram of WECS}

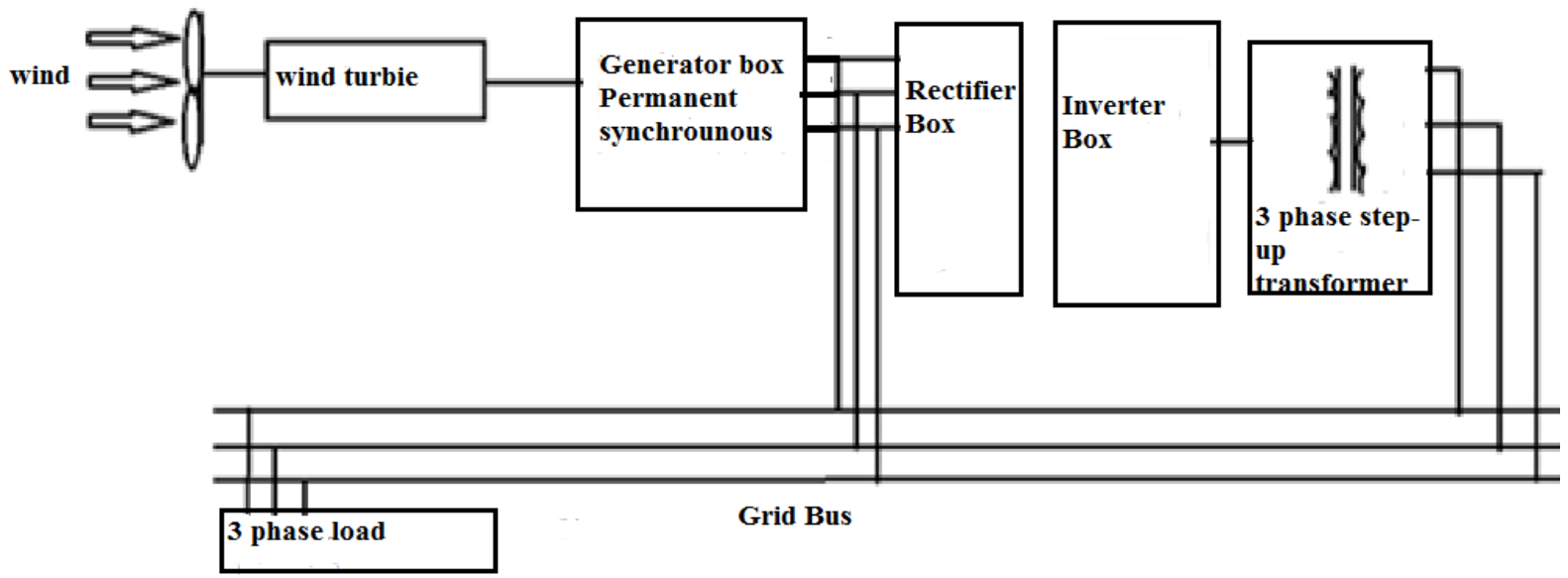

Fig no.1 Block diagram of wind energy conversion system

2. Wind Energy conversion:

Kinetic energy of wind is given by the following equation:

$$
E_{c}=\frac{1}{2} m v^{2}
$$

$\mathrm{M}=$ Air mass, $\mathrm{V}=$ wind speed, $\mathrm{p}=$ air density, $\mathrm{s}=$ covered surface of the turbine

Wind power is given by

(3.1)WIND TURBINE MODEL:

$$
P_{w}=E_{c}=\frac{1}{2} m_{v^{2}}=\frac{1}{2} \rho S_{v^{3}}
$$

Wind turbine is systems that harness the kinetic energy of the wind for useful power. 


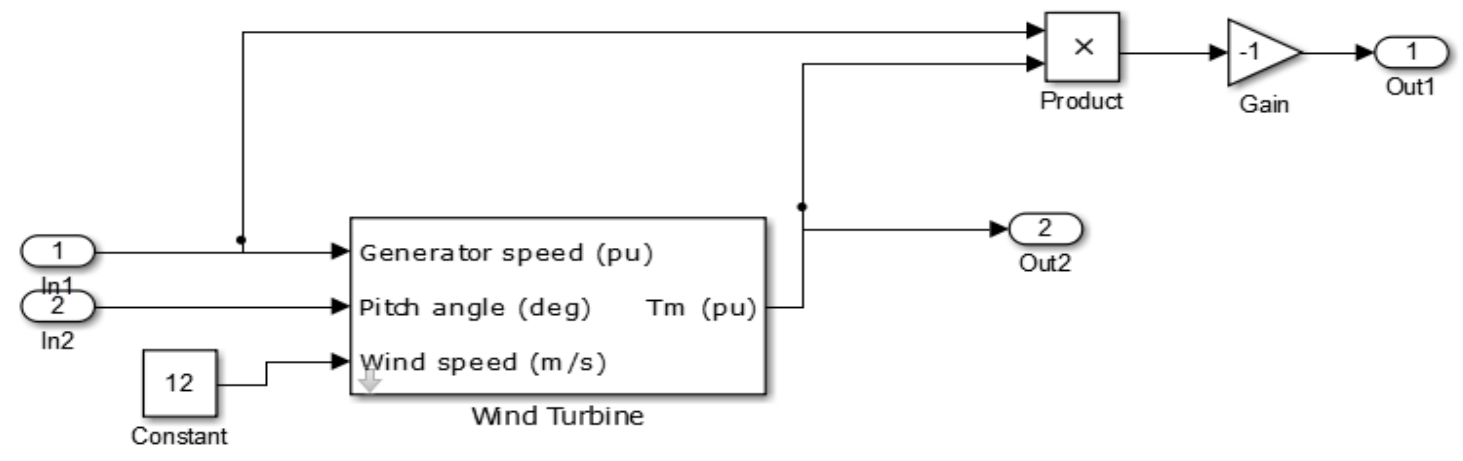

Fig no.2 Simulink model of wind turbine

The aerodynamic power of wind turbine is $P_{m}$ is express [4]

$$
P_{m}=0.5 C_{p}(\lambda, \beta) \rho A_{v^{3}}
$$

Where $\rho$ is the air density and $\mathrm{A}$ is the blades swept area

$\mathrm{V}=$ Wind speed

$C_{p}=$ Power coefficient

$\beta=$ Pitch angle

$\lambda=$ Tip speed ratio

$\lambda=\frac{R W_{m}}{V}$

$W_{m}=$ Rotor speed of the wind speed

The power coefficient of the wind turbines indicates

$$
C_{p}(\lambda, \beta)=C_{1}\left(\frac{C_{2}}{\lambda_{i}}-C_{3} \beta-C_{4}\right) e^{\frac{-C_{5}}{\lambda_{i}}}+C_{6} \lambda
$$

$\frac{1}{\lambda_{\mathrm{i}}}=\left[\frac{1}{\lambda+0.089}-\frac{0.035}{\beta^{2}+1}\right]$

When pitch angle $\beta=0$ and bi speed ratio $\lambda=6.325 C_{p}$ is maximum value

$C_{p}$ Of the turbine is the divided by wind power and function of the wind speed, rotational speed, pitch angle. Output of the turbine is the torque applied to the generator shaft is per unit of the generator.

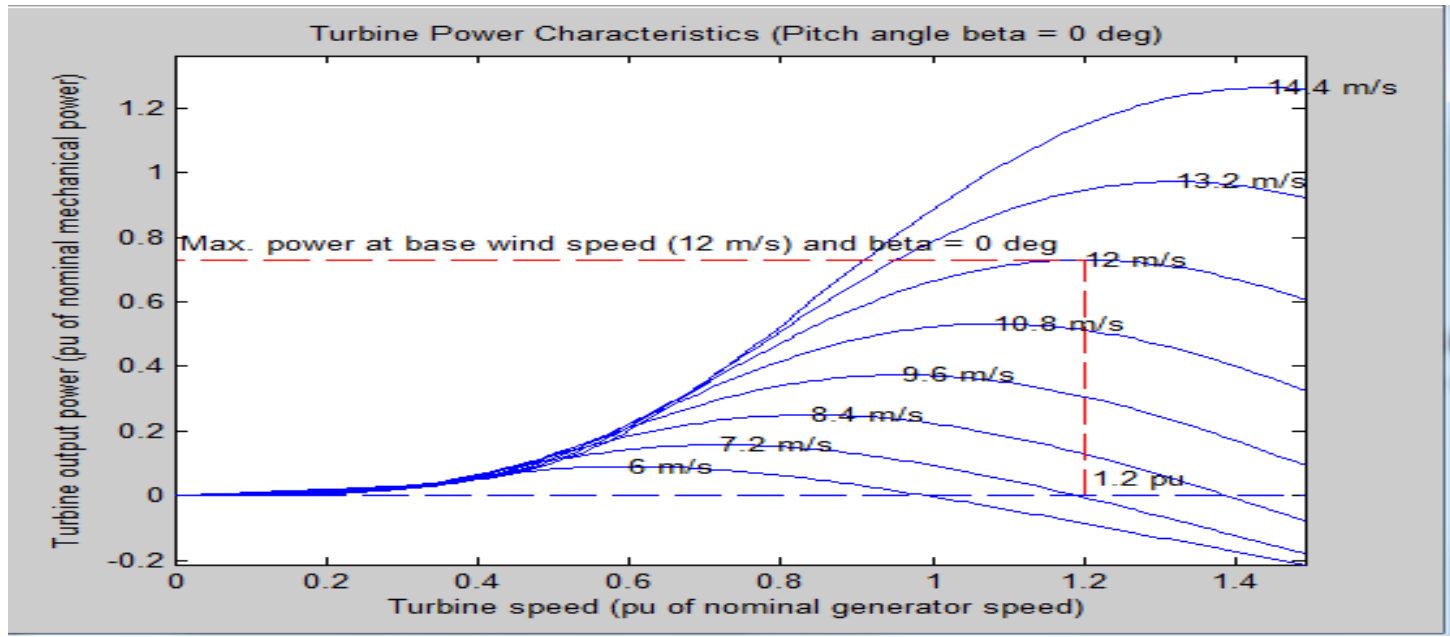

Fig no3 Characteristics of Wind turbine

(3.2) MODELING Of PMSG:

PMSG is used in WECS because of its advantage such as better reliability, lower maintenance and more efficient [4]. The model of PMSG is established in the d-q synchronous frame as shown in fig 4 


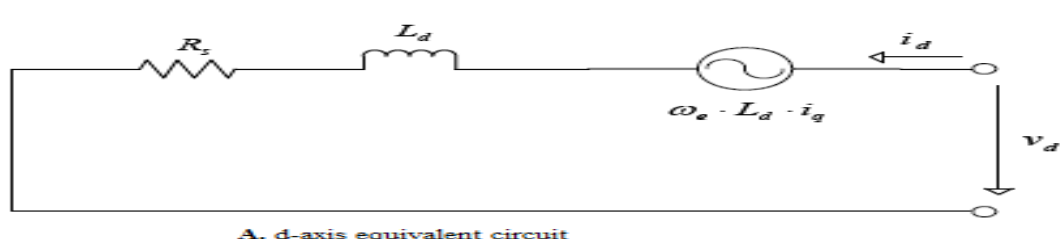

A. A-axis equivalent circuit

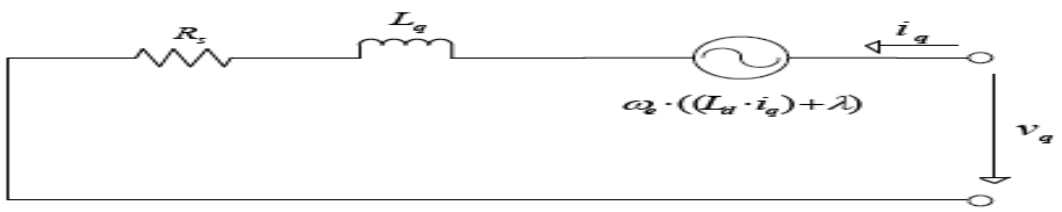

B. q-axis equivalent circuit

Fig no.4 Equivalent Circuit of PMSG in d-q reference frame

The voltage equations of PMSG as shown in Fig. 4 are given by [5]

$$
\begin{aligned}
& \frac{d}{d t} i_{d}=\frac{1}{L_{d}} V_{d}-\frac{R}{L_{d}} i_{d}+\frac{L_{q}}{L_{d}} \rho w_{r} i_{q} \\
& \frac{d}{d_{t}} i_{q}=\frac{1}{L_{q}} V_{q}-\frac{R}{L_{q}} i_{q}+\frac{L_{d}}{L_{q}} \rho w_{r} i_{d}-\frac{\lambda \rho w_{r}}{L_{q}}
\end{aligned}
$$

The electromagnetic torque equation is given by

$$
T_{e}=1.5 \rho\left[\lambda i_{q}+\left(L_{d}-L_{q}\right) i_{d} i_{q}\right]
$$

Where $L_{q}=\mathrm{q}$ axis inductance

$L_{d}=\mathrm{d}$ aixs inductance

$i_{q}=\mathrm{q}$ axis current

$i_{d}=\mathrm{d}$ axis current

$\mathrm{R}=$ resistance of the stator winding

$V_{q}=\mathrm{q}$ axis voltage

$V_{d}=\mathrm{d}$ axis voltage

$w_{r}=$ angular velocity of the rotor

$\lambda=$ amplitude of flux induced

$\rho=$ number of pole pairs

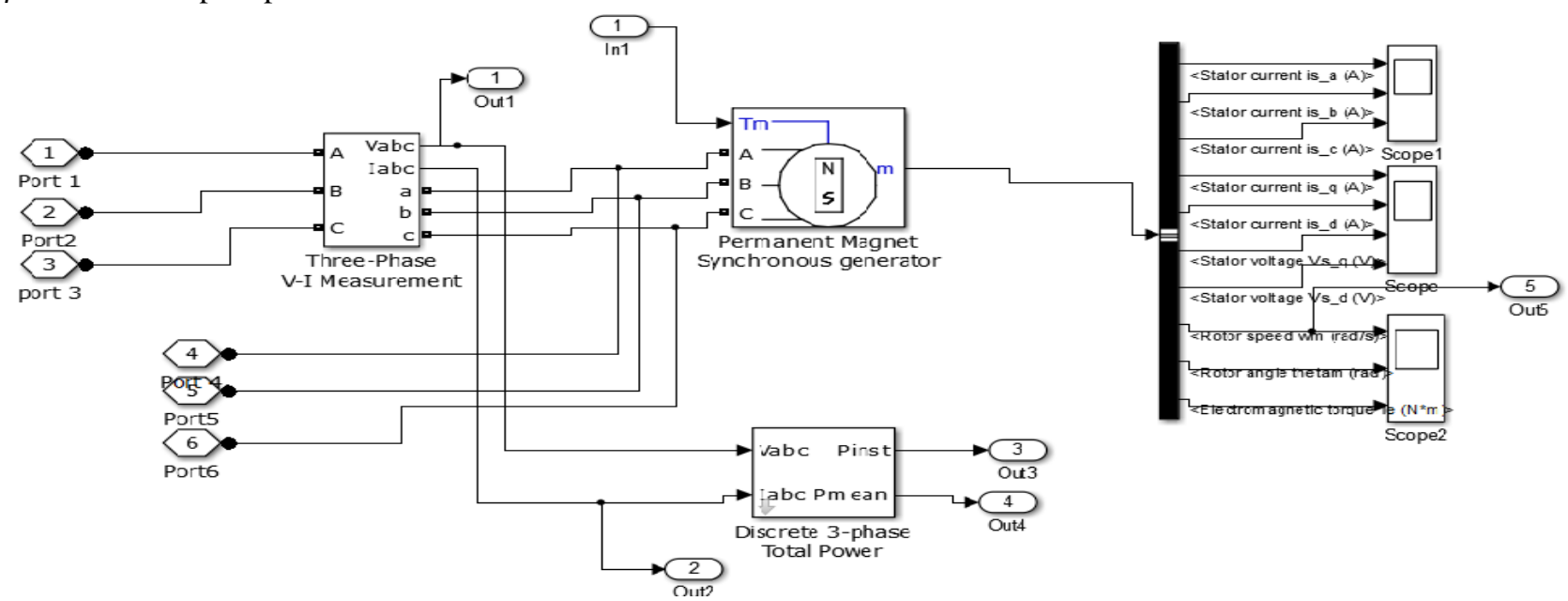

Fig no.5 Simulink model of PMSG

(3.3)RECTIFIER MODEL: Phase controlled AC-DC converters employing thyristors are extensively used for changing constant ac input voltage to controlled dc output voltage. Fig no.6 shows the simulink model of threephase bridge rectifier. The configuration does not need any special transformer, and works as a 6-pulse rectifier [6]. 


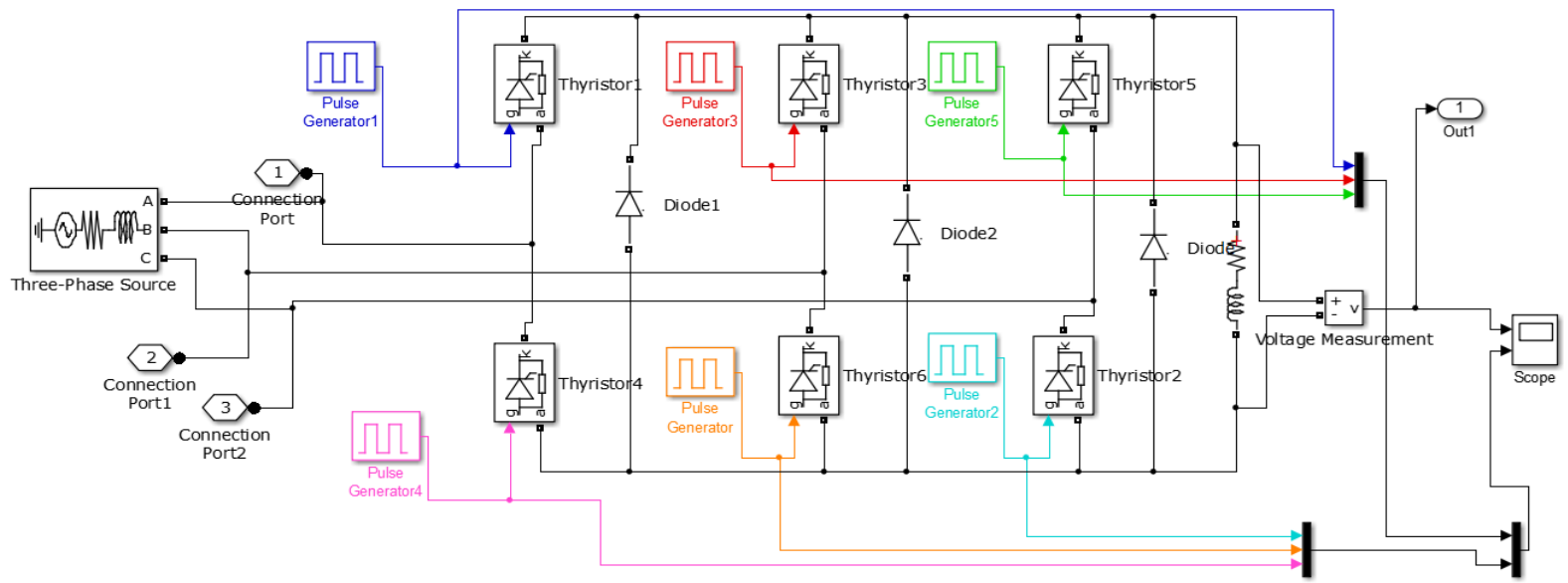

Fig no.6 Simulink model of Rectifier

(3.4)INVERTER MODEL: Inverter converts the dc power into 3 phase ac power. The inverter that we have used here is an IGBT-Diode based inverter connected in the bridge configuration. Universal bridge inverter used here to present bridge inverter.

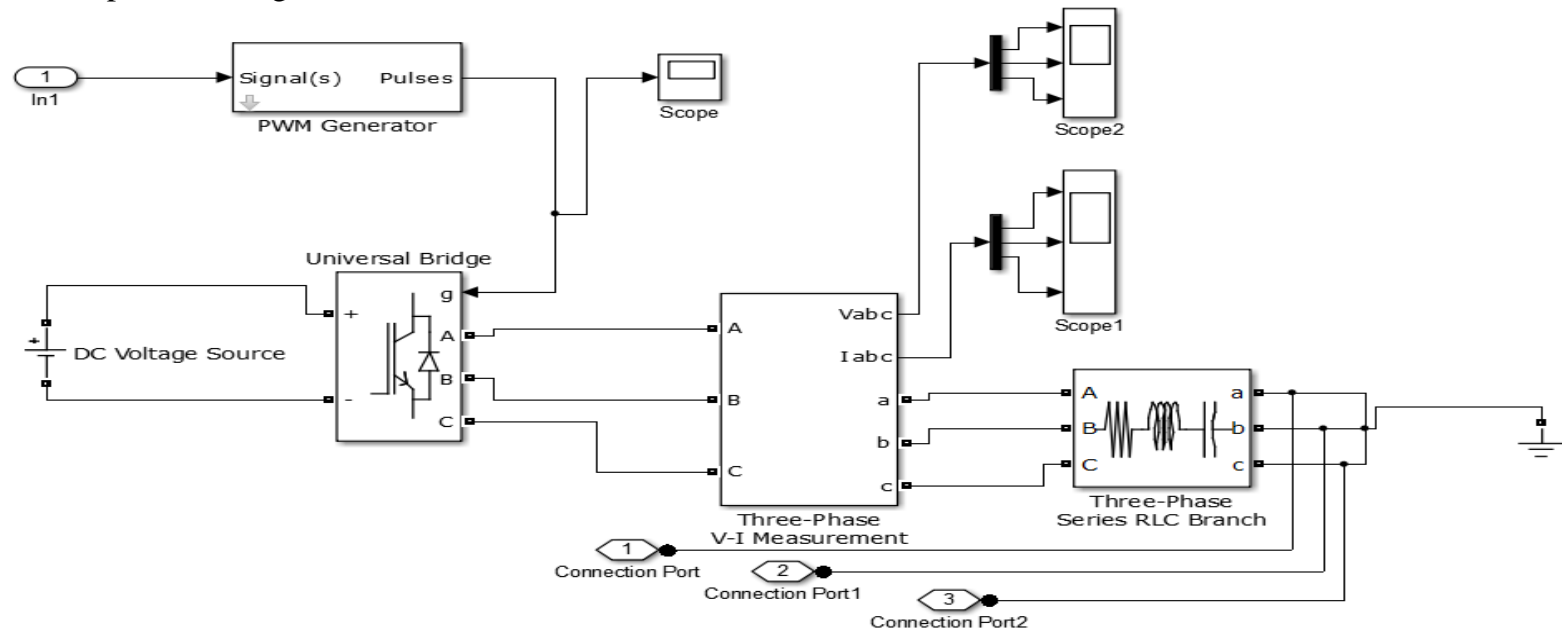

Fig no.7 Simulink model of Inverter

\section{SIMULINK MODEL OF OVERALL SYSTEM}

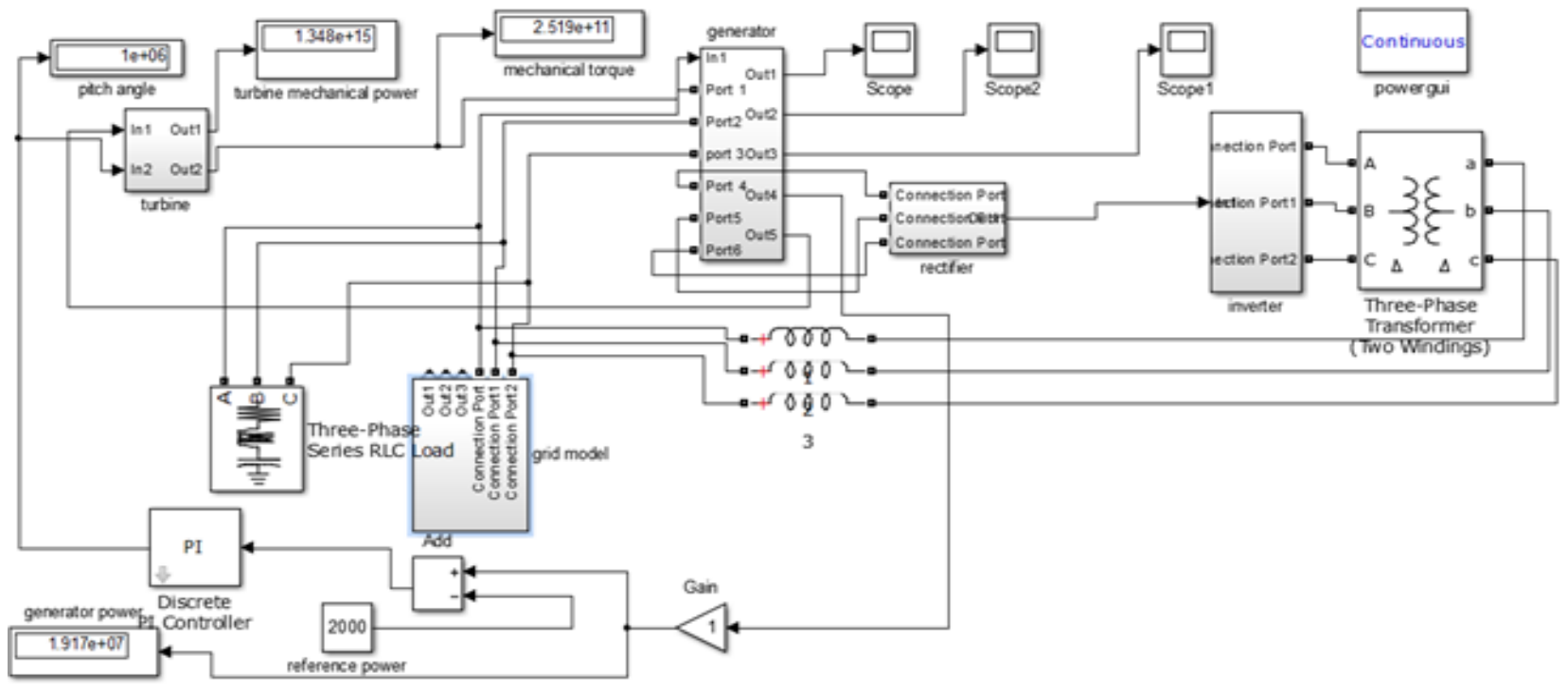

Fig no.8 Simulink model of system 


\section{SIMULATION RESULTS}

This wind energy conversion system built via Matlab/Simulink. In this paper, the base speed is considered as $12 \mathrm{~m} / \mathrm{s}$. The output voltage is 660 volt at $50 \mathrm{~Hz}$. The simulation results are shown below:

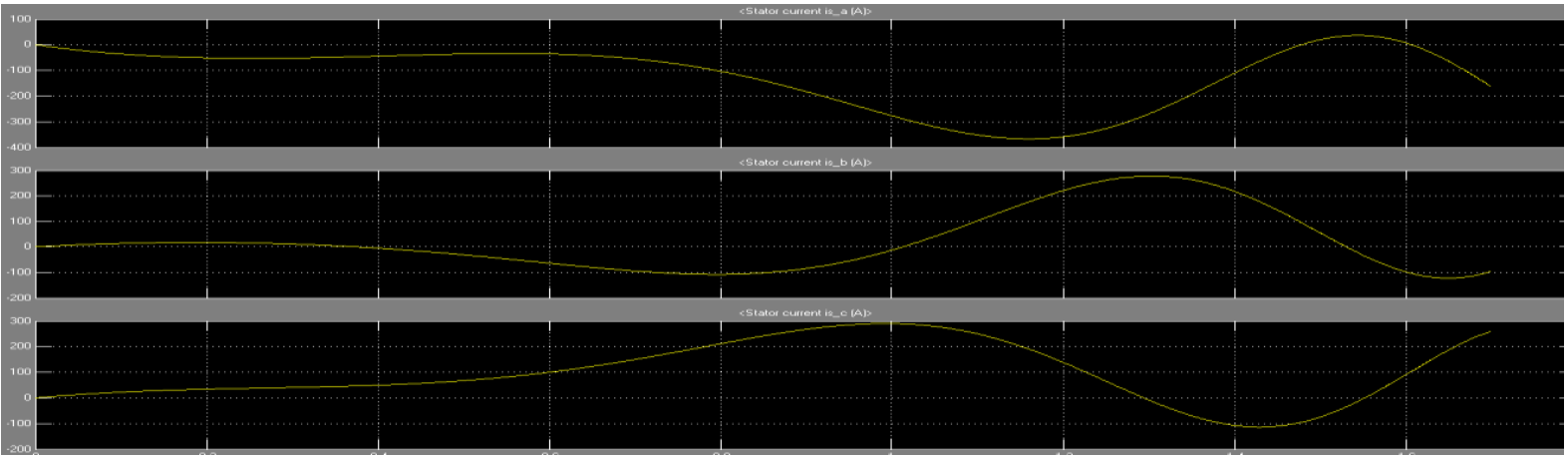

Fig no.9 Waveforms of PMSG q-axis current and d-axis current

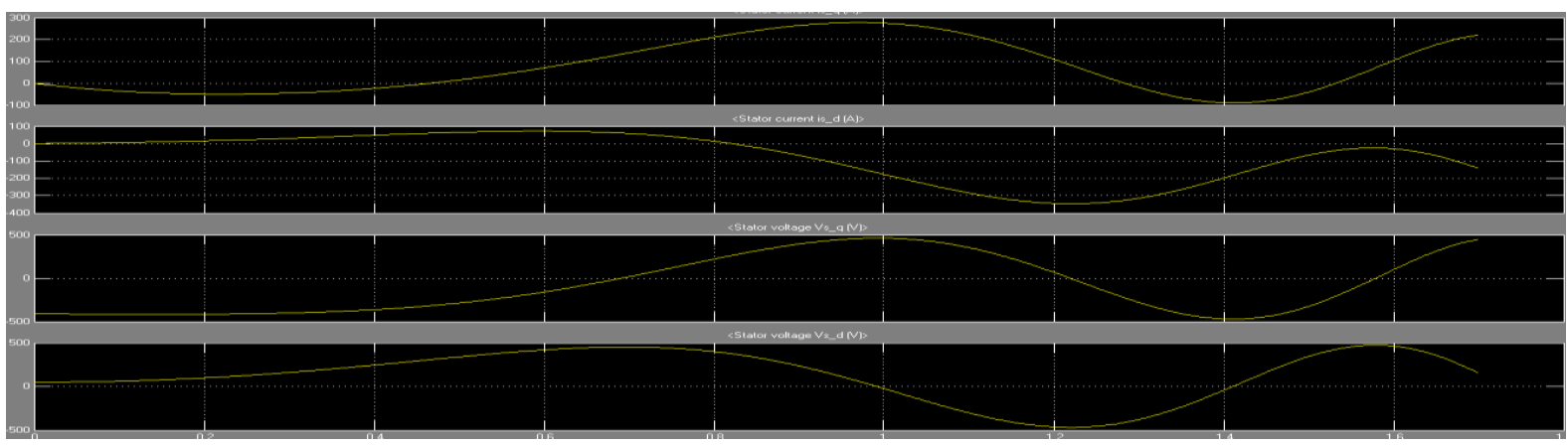

Fig no.10 Waveforms of PMSG Stator current in d-q axis

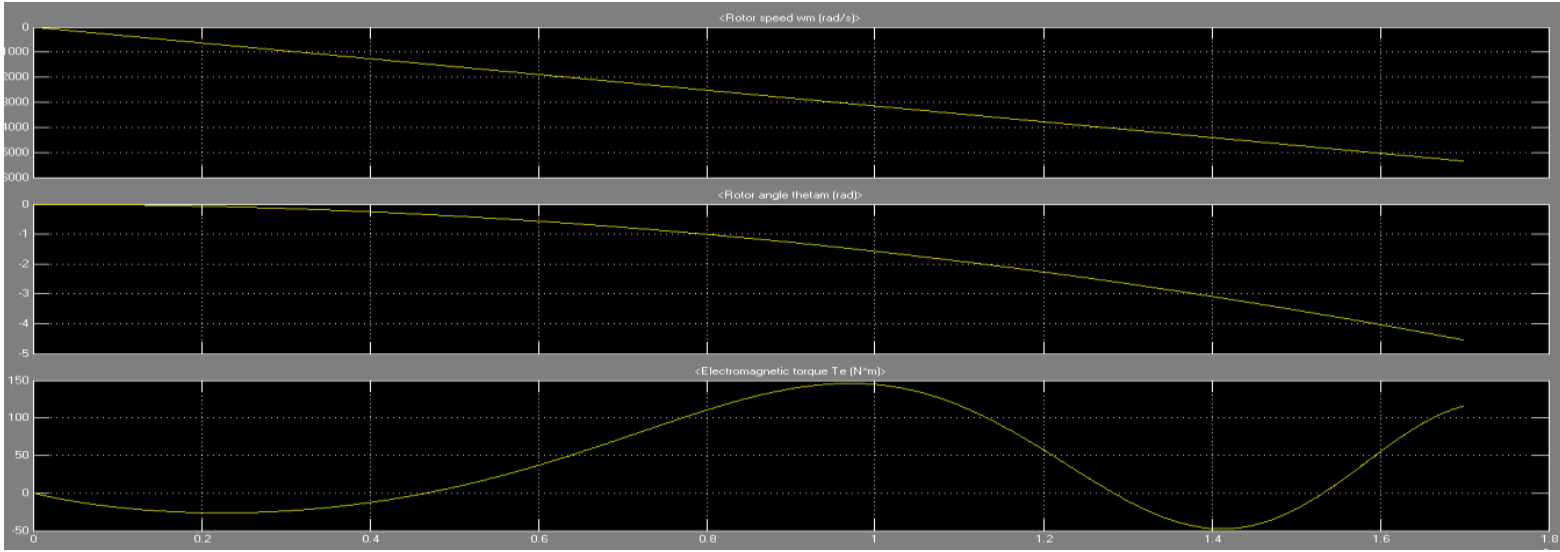

Fig no.11 Waveforms of Stator speed, angle and electromagnetic torque 


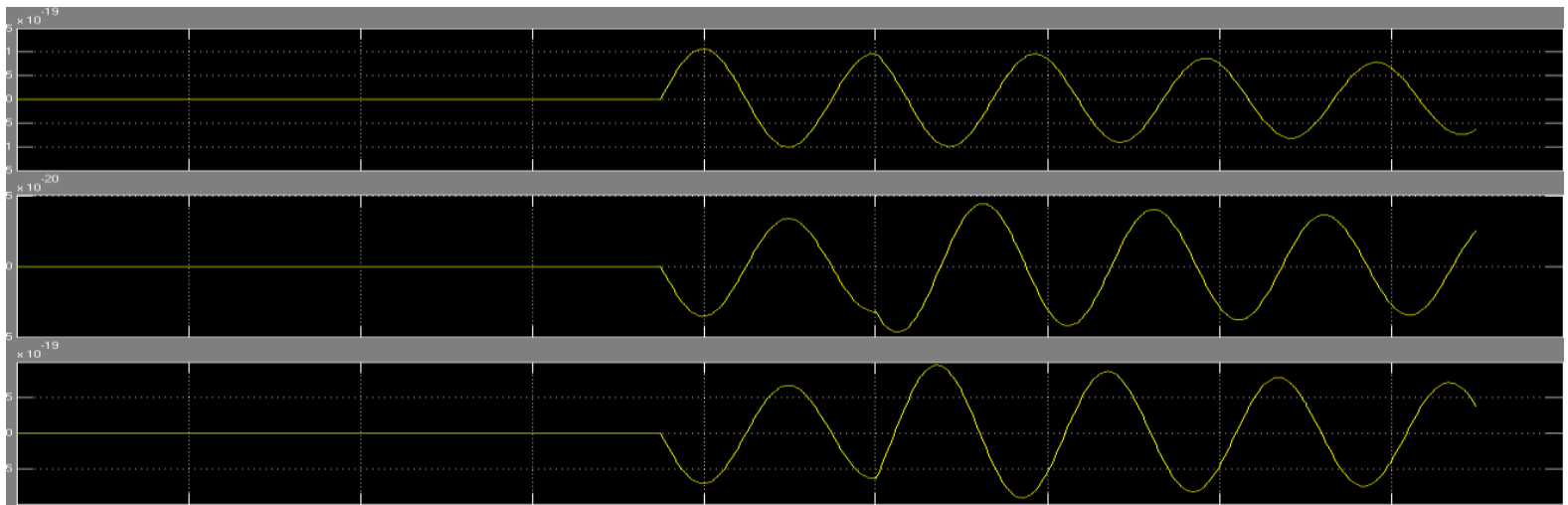

Fig no.12 Output current of inverter

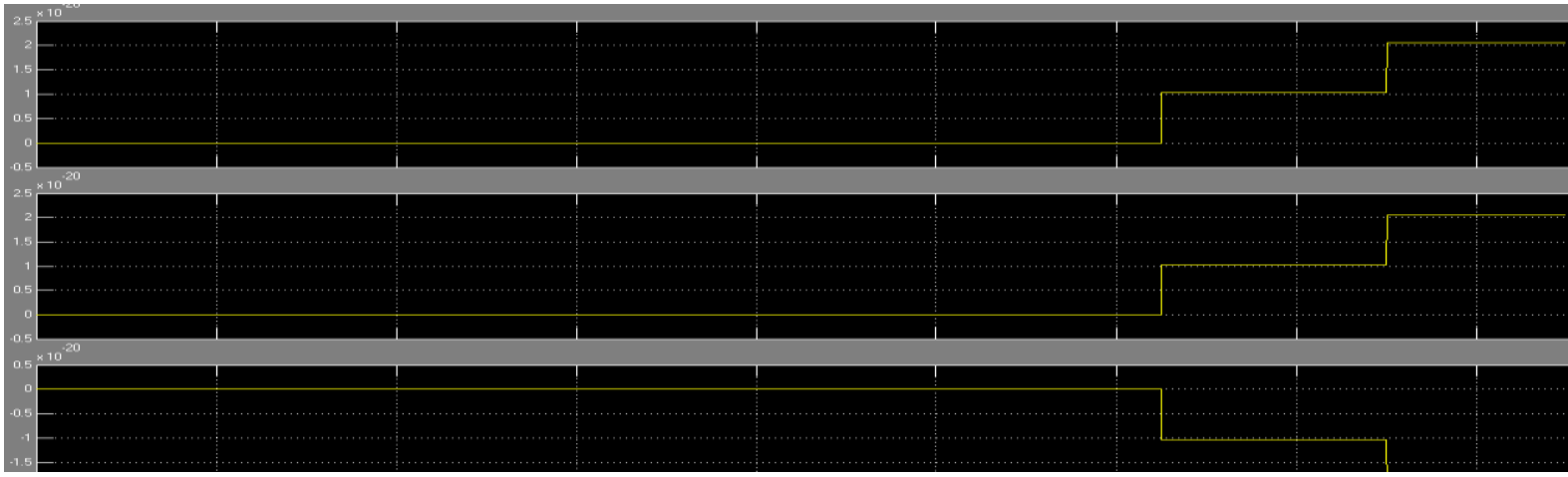

Fig no.13 Output voltage of inverter

\section{CONCLUSION}

This paper described the modeling of PMSG with WECS. IT consist wind turbine, PMSG, rectifier, inverter and grid model. The model has been implemented in MATLAB/SIMULINK. The PMSG has been modeled in the dq model. Simulation results show the steady state performance of the wind energy conversion system (WECS).

\section{REFERENCES}

[1] S. Samanvorakij, P. Kumkratug "Modeling and Simulation PMSG based on Wind Energy Conversion System in MATLAB/SIMULINK” Proc. of the Second Intl. Conf. on Advances in Electronics and Electrical Engineering — AEEE 2013

[2] M.Ying, G.Li, M.zhou, and C.Zhao, "Modeling of the wind turbine with a permanent magnet synchronous generator for integration," IEEE, pp.1-6, 2007.ISBN1-4244-1298-6

[3] Suman Nath, Somnath Rana “The Modeling and Simulation of Wind Energy Based Power System using MATLAB” International Journal of Power System Operation and Energy Management, ISSN (PRINT): 2231-4407, Volume-1, Issue-2, 2011

[4] A. B. Cultura and Z. M. Salameh, “Modeling and Simulation of a Wind Turbine-Generator System” 978-1-4577-1002-5/11@2011 IEEE

[5] S. Saikuma, S. Saravanan, and R. V. Sandip, "Modeling and Control of a Wind Turbine using Permanent Magnet Synchronous Generator”, IJEST, Vol3, no., pp.2377-2384, 3 March 2011.

[6] "Three-Phase Full wave Controlled Converters (Controlled rectifier)" University of Technology Laser and Optoelectronics Engineering Department Laser Engineering Branch Power electronics 2011-2012 